\title{
Editorial
}

\section{A point regarding case reports}

nother year comes to an end. We are all home after a splendid meeting in the hallowed premises of the National Defence Academy, Pune. The President and his colleagues have worked hard for us and left us even richer in knowledge and skills.

With a sense of pleasure I present before you this issue of the journal, which comprises an amalgamation of interesting original works as well as case reports. Whether case reports merit publication has invariably been debated. There are those who say that a 'quality' journal discourages case reports and focuses on 'Original' works. I have thought regarding this for long and would respectfully disagree. Permit me to present my case before you. Case reports represent the communication between a colleague and his peers regarding a case that has confused, stimulated or taught him an important lesson in medicine. For a case report to be considered by a journal, it requires to be of sufficient rarity. The concerned author needs to do considerable background research and finally collect all the material and write the report. This is not an easy task and certainly deserves positive response from the editors. I think case reports are often invaluable if an author encounters a similar case not only already reported by another author but also which has provided the literature search, outcome and some valuable tips. They enable the author to manage the patient with greater knowledge and with the accumulated experience. This is what journals are for - to serve as a knowledge bank, accessible to the concerned clinical community, so that collectively we, as plastic surgeons are better informed regarding the challenges before us.

This issue also contains certain valuable data regarding the epidemiology of burns in India. It not only makes for an interesting reading but also makes one introspect regarding the state of medical services available for burn patients in our country. It is heartening to know that authors are now documenting their cases and releasing data, which will be of use to the clinical community as well as to the planning professionals. The article regarding the Sanskrit language too is the most unusual, and in my opinion, extremely useful at least to those whose native languages are from one of the languages spoken in the subcontinent. In all languages, the consonants and vowels are taught in the same style- automatically sorted according to the mechanism of their production. The conclusions of the author were remarkable; however; none of us were affected like him. The most important things are often the simplest.

I wish all our readers a very happy, peaceful and prosperous new year.

\section{Mukund Thatte}

Indian Journal of Plastic Surgery, Editor, Indian Journal of Plastic Surgery, $4^{\text {th }}$ Floor, 770 Vimal Smruti, Ghanti Road, Parsi Colony, Dadar, Mumbai - 400 014, India. E-mail: editor@ijps.org 